\title{
Delays, confusion over rules hinder EC research projects
}

\begin{abstract}
Munich. Bureaucratic obstacles are slowing progress in three research programmes sponsored by the European Commission (EC), frustrating applicants faced with unclear instructions and changing rules and angering those who succeed by making them wait for their money.

Most of the 15 programmes being funded under the commission's current research plan, which allocates ECU5.7 billion (US\$6.8 billion) over five years, are running smoothly. The plan, known as Framework 3 , is intended to encourage cooperative efforts by requiring proposals from laboratories in more than one country. But there are problems with three programmes: the ECU131-million Biomed programme, which supports biomedical and health research; the ECU1.3-billion ESPRIT programme, which supports information technology; and the ECU488-million Human Mobility programme, which offers researchers the chance to move around Europe to gain expertise in techniques not available in their own regions.
\end{abstract}

The Biomed programme has been frustrated by feuds between the commission and its advisory committee over how applica- tions will be peer-reviewed. The normal procedure is a two-tier process, with an initial screening to weed out the best applications followed by a more comprehensive review to decide funding.

In the case of Biomed, some 1,900 proposals are competing for only 100 grants. The programme's advisory committee, mostly heads of research councils or departments of health from each of the 18 participating countries, decided to invite 300 to submit full applications. But Filippo Pandolfi, the EC commissioner for research, changed the rules.

Bowing to pressure from groups that felt they had not been properly represented, Pandolfi asked the commission to give assessment scores to all applicants and invite them to proceed to the next step. This angered the committee, which unanimously refuses to back down from its earlier decision. It argues that a full review of lowpriority proposals would waste the time of both scientists and reviewers.

More than 700 full applications have been received, but none has yet been put out for peer review. The reviewers were chosen for discipline-orientated assessment groups last November, but they have not yet been called.

By contrast, proposed research under the ESPRIT programme has been peer-reviewed, but few of the successful applicants have received their money. The delay stems mostly from the commission's decision to go by the book after an unrelated decision that had not been ratified by all the commissioners was successfully challenged in January.

The administrators of ESPRIT, which received more than a thousand applications by its closing date last October, are now making sure that each grant decision is approved by each commissioner. So far, of the 300 successful applicants, 65 have had their grants fully approved and 140 more are expected to go out shortly. Two more batches will be completed by the end of the year. Officials at the commission say that they have also been slowed by the unexpectedly large number of applicants and the legal changes needed to administer research and development funding according to new rules written into the Maastrict Treaty, which prepares member countries for European unity.

The Human Mobility programme is intended as a way to distribute expertise throughout Europe; in practice, this means scientists from the poorer countries of southern Europe moving north. The start of the programme was delayed for several months, and when it was finally launched early last month applicants were given a deadline of only two to three weeks. In addition, the

\section{China relaxes rules for visiting citizens}

Beijing. China has adopted new rules that will make it much easier for Chinese nationals living and working in other countries to return for a visit. The changes all but abolish a system introduced shortly after the massacre at Tiananmen Square in June 1989 that severely restricted Chinese visitors wishing to return to positions outside China.

The decree, which took effect on 1 July, stipulates that anyone with a valid passport and an entrance visa to another country will be allowed to leave China freely. Mao FengPing, director of the exit and entrance administration bureau in the Ministry of Public Security, says that the new rules apply "no matter how much time passes between the trip to China and the flight home and even if the country is different from where the visitor began his journey". The visitor need not obtain a visa inside China, nor need the passport be issued by mainland authorities. Under the former system, which required an 'exit registration card', such travel was nearly impossible.

Chinese scientists have long advocated the dropping of such restrictions because of the harm done to the country's research institutions. Talented young scientists who do not think they will be allowed to leave
China will choose to stay abroad. Similarly, the policy limits attendance at scientific conferences. For example, officials from the American Physical Society are concerned about attendance at an international conference on semiconductors in Beijing because of a lack of assurances from their hosts that all participants would be allowed to leave the country at the end of the conference, due to begin on 10 August.

The new rules will make life easier for Chinese researchers and students living outside China. The possibility of being retained during a visit to see family or attend a conference has exacted a high price from researchers who choose to live and work in another country. It was also a deterrent for Western scientists thinking about hiring Chinese nationals.

"When I heard that he wanted to go back to China for a visit before starting work here, I thought that I might never see him again", says Ellen Williams, a physicist at the University of Maryland, about Yunong Yang, a postdoctoral researcher who joined her laboratory a few months ago. "None of my Chinese students has ever had a problem, but you always worry."

In fact, Yang was forced to cancel his travel plans after US officials told him that they needed six months to renew his passport. "They told me that they have to write to China and make sure everything is in order", he says, "and that sometimes they wait a long time before they get any answer. I couldn't wait that long." But Yang sent his wife and children, and they returned last month without incident.

Researchers within China are also happy with their newly granted freedom. For $\mathrm{Li}$ Ru-Jing, who completed his graduate training in Britain before returning to Beijing, the new rules may end an 18-month hiatus in his scientific career. "Now the ball is in my court", he says. "The test is whether I can find a foreign institute who wishes to take me in."

The change is part of China's campaign to open itself to the outside. The theme was sounded by party leader Deng Xiao-Ping during a tour of South China earlier this year and echoed by deputies at the National People's Congress in April. It may also reflect the country's need for hard currency from the West, along with a realization that excluding some of its most productive citizens is a poor way to stimulate economic growth.

You Qin Li 
application forms from Brussels were so badly drawn up that nearly everyone requested further clarification.

The delay is due to confusion over how to incorporate political as well as scientific criteria into its assessment, with priority given to applicants from poorer countries. But EC officials cannot extend the deadline for applications because the ECU109 million available for 1992 will be lost if it is not spent by the end of the year. Late applications will be considered in 1993.

Although these problems provide a disincentive to many scientists, the lure of EC funds is irresistible. Young research fellows are offered salaries at nearly twice the going rate; at ECU45,000, they compare with those paid to department heads. Norman Bowery, professor of pharmacology at the University of London's School of Pharmacy, says that the short deadlines and ambiguous application forms put a lot of pressure on researchers, "but we can't not do it. There is so much money to be had."

In addition, researchers from poorer countries welcome the opportunity to compete for grants from outside their own governments. Rebecca Matsas, senior researcher in neurobiology at the Hellenic Research Institute in Athens, believes that the process is useful even if no grant is made. "It's hectic, but the interactions give you a chance to get to know a lot of people", she says. "It's good for future collaborations."

Alison Abbott

\section{Scientific panel continues work on whaling ban}

London. The moratorium on commercial whaling remains in place following last week's meeting of the International Whaling Commission (IWC) in Glasgow. Although a Revised Management Procedure that the commission's scientific committee had been working on for the past seven years was accepted (see Nature 357, 350; 1992), it must clear other administrative hurdles before it takes effect.

During the next 12 months, the scientific committee must develop minimum data standards, guidelines for conducting surveys and analysing the results and relevant computer programs. All this must be written into language that can withstand legal scrutiny.

Although a French plan to create an Antarctic sanctuary was withdrawn before the meeting opened, the commission decided to review the proposal for its next meeting, a year from now, in Japan. A working group of the scientific committee will hold meetings with such groups as the Commission for the Conservation of Antarctic Marine Living Resources and the Scientific Committee for Antarctic Research.

lan Mundell

\section{US oceanography lab sinks under weight of politics}

Even congressional pork can go off. On 30 September, the US Navy will close its Institute for Naval Oceanography (INO) at Bay St Louis, Mississippi, thus dismantling part of the monument to himself that John Stennis built over a 42-year career in the US Senate. The collapse of the laboratory may be a warning that those who rely on powerful congressmen for launching new projects may find themselves stranded once those backers are gone or lose interest.

INO, the youngest of several naval projects at what is known as the Stennis Space Center, results from a deal struck in 1985 between Stennis, then a senior member of the Senate Armed Forces Committee and chairman of the Appropriations Committee, and John Lehman, then Secretary of the Navy. Stennis, angered by Lehman's decision to base in San Francisco a battleship he had coveted for Mississippi, was placated with the INO, planned as a bridge between the Navy and the academic research community. Among other things, INO would have used supercomputers and remote sensing data to forecast oceanographic conditions, much as meteorology has made weather forecasting possible.

Lehman's decision to locate INO in Mississippi contradicted the scientific advice and also the wishes of those nominated to work there, who favoured the Navy's research complex at Monterey, California. But Christopher Mooers, INO's first director, began on an upbeat note, with a staff of 30 and an annual budget of $\$ 4$ million and the ambition to attract others "with a pioneering spirit" (see Nature 324, 6; 1986).

But it has since been downhill all the way. The budget has steadily declined to $\$ 3.2$ million, about two-thirds the value of that in 1986. The Cray Y-MP on which INO had set its heart went to the Oceanographer of the Navy instead (but INO researchers are allowed to use it). Mooers was forced to resign in 1989 after a management dispute, and since then there have been three directors. Mooers says that most of the original staff have left, like many of their successors. "Retention has turned out to be even more difficult than recruitment", he points out.

Where does the blame lie? Most people give Stennis the lion's share, both for snatching INO from its preferred site in California and for his almost total lack of interest afterwards. "It was the barrel without the pork", says Mooers.

INO, created as a civilian centre to encourage cooperation between the Navy and universities, has been managed from the outset by the University Consortium for Atmospheric Research (UCAR), a group of 59 universities with interests in atmospheric research and oceanography. But the pairing proved to be a poor fit. UCAR's only members in southern states are from Florida and Texas. INO also suffered from the successive reorganizations of naval research, which have finally put it under the wing of the Naval Research Laboratory, which has its own university collaborations and has not

Christopher Mooers, former INO director (left); aerial view of institute (below). been looking for UCAR's help.

Wayne Shiver, assistant to UCAR's president, says it has been clear from the start that the Navy would never provide the funds needed to let its newest and weakest research institution attain critical mass. In addition to insufficient funding, INO also suffered from the absence of a meaningful strategic plan and a vision of its place in the Navy's world. UCAR threw in the towel earlier this year, notifying the Navy that it wished to end its responsibility for INO. That was the death knell for the laboratory.

It remains to dismember INO, keeping the pieces worth saving. The ocean modelling programme will probably go to the University of Southern Mississippi and the Experimental Center for Mesoscale Ocean Prediction to Mississippi State University. The Navy will guarantee funds for two years, but then the programmes will have to compete for further grants. Most of the 31 people still at INO, including about 20 scientists, will be kept in one capacity or another. "We're trying to make the best of a bad situation", says Shiver.

Christopher Anderson 